\title{
INFORMASI DIAGNOSTIK GAMBARAN RADIOGRAF CERVICAL HASIL MULTIPLANAR RECONSTRUCTION CT-SCAN KEPALA
}

\author{
$\underline{\text { Panji Wibowo Nurcahyo }{ }^{1} \text { Merliana Devina }{ }^{2} \text { Akhmad Haris Sulistiyadi }{ }^{3} \text { Siti Daryati }}{ }^{4}$ \\ 1,2,3,4 Poltekkes Kemenkes Semarang \\ Corresponding author: Panji Wibowo Nurcahyo \\ Email: Panjitrrpwt@gmail.com
}

\begin{abstract}
Introduction : Data at Kenyatta National Hospital (KNH) from 2012 to 2016 recorded that there were 1,432 patients with a head injury diagnosis. Of the patients diagnosed with moderate or severe head injury, $11(3.07 \%)$ patients had head and neck injuries. The clinical pathway in the diagnosis of head injury, CTScan of the brain (preferably with the inclusion of the cervical vertebrae) is now the rule in assessing traumatic brain injury. At the Radiology Installation of the Salatiga City Hospital, a head CT scan with a head injury diagnosis used a scan of the area from cervical 7 to the vertex, then cervical radiographs were made using MPR.

Methods : This study uses a qualitative method with a case study approach. Data collection was carried out in March 2020 by direct observation, in-depth interviews, and documentation studies.

Results : Patients diagnosed with CKS and CKB were shown cervical MPR. This MPR image has no superposition, which usually shows cervical 1 and 2 superposition with the mandible even at an angle, and in the lateral projection, cervical 7 superposition with the shoulder. The disadvantage is that the radiation dose received by the patient increases, but on radiological examination there is a justification principle, namely even though using a CT-Scan with greater radiation, the benefits obtained are also greater. In addition, burst fractures can be seen on cervical radiographs from MPR. There are fractures in trauma victims that are not fully demonstrated on radiographs at cervical 1 to cervical 2, cervical 6 to 7 cervical levels, and most involve the transverse process because the patient is uncooperative. Helical CT scanning can depict significant fractures that cannot be demonstrated on conventional radiographs and should be added to the initial screening for suspected cervical trauma.

Conclusion : The cervical MPR image aims to obtain four cervical projections, namely AP, lateral, right oblique, and left oblique without conventional projections with the aim of minimizing movement in patients who are at risk of aggravating spinal cord injury. Diagnostic information from MPR results is to obtain structural visualization. specific, determine the extent of the lesion, localize the lesion and bone fragments. However, the radiation dose received is greater than conventional radiographic examinations.
\end{abstract}

Keywords : Cervical; Multiplanar Reconstruction; Head CT Scan

\section{Pendahuluan}

Data di Kenyatta National Hospital $(\mathrm{KNH})$ pada tahun 2012 hingga 2016 mencatat bahwa terdapat 1.432 pasien dengan diagnosa cedera kepala. Dari kasus ini, $358(25 \%)$ pasien mengalami cedera kepala sedang dan berat, sisanya $1074(75 \%)$ pasien mengalami cedera kepala ringan. Dari pasien diagnosa cedera kepala sedang atau berat, $11(3,07 \%)$ pasien mengalami cedera kepala disertai cedera tulang belakang leher (Kiboi, 2019). Data dari oktober 2011 hingga oktober 2012 melibatkan 369 pasien cidera kepala sedang dan berat terdapat $42(11,38 \%)$ pasien ditemukan memiliki cedera tulang belakang leher. Semua pasien yang cedera kepala harus dicurigai mengalami cedera tulang belakang leher. (Nazir, 2012). Salah satu pemeriksaan penunjang diagnosa yang biasa digunakan pada pasien dengan trauma kepala adalah CT-Scan.

Salah satu program komputer pada CT-Scan memungkinkan dilakukan multiplanar reconstruction yaitu format ulang gambaran sagital, paraxial, dan coronal dari kumpulan gambaran axial yang berdekatan. Multiplanar reconstruction memiliki kelebihan untuk mendapatkan visualisasi struktur spesifik, menentukan luasnya lesi atau 
fraktur, membantu melokalisasi lesi, fragmen tulang, atau benda asing. Namun kualitas gambaran multiplanar reconstruction detail gambarnya tidak sebagus yang diperoleh pada gambar axial, tergantung pada kualitas gambar axial, sehingga penting agar pasien tidak bergerak atau bernapas selama scanning. Selain itu, ketebalan bidang memengaruhi detail gambar; dengan demikian bidang tebal menghasilkan kekaburan dan hilangnya detail struktural. MPR memungkinkan memperoleh gambaran cervical seperti radiograf proyeksi AP, Lateral, Oblik pada pemeriksaan radiografi konvensional.

\section{Metode}

Jenis penelitian adalah penelitian kualitatif dengan pendekatan studi kasus yaitu penelitian yang bertujuan untuk memberikan gambaran secara detail pada keadaan sebenarnya di lapangan pada tingkat realita dan keadaan sesungguhnya. Tempat pengambilan data pada penulisan Karya Tulis Ilmiah ini adalah Instalasi Radiologi RSUD Kota Salatiga dan waktu pengambilan data dilakukan pada bulan Maret 2020. Pengambilan data dilakukan pada bulan Maret 2020 dengan observasi langsung, studi dokumentasi dan wawancara mendalam terhadap 2 orang radiografer, 1 orang dokter spesialis radiologi, 1 orang dokter pengirim dari IGD dan pasien. Analisis data dalam penelitian ini dilakukan dengan "Interaktif Model"

\section{Hasil Dan Pembahasan}

Gambaran cervical hasil MPR CT-Scan dapat meminimalkan gerakan pada pasien agar mengurangi resiko yang dapat memperberat cedera tulang belakang jika pasien harus dipindahkan ke ruang pemeriksaan radiografi konvensional. Namun dosis radiasi yang diterima pasien akan bertambah besar karena area scaning pada CT Scan kepala tersebut dimulai dari Cervical 7 sampai vertek dengan slice thickness $5 \mathrm{~mm}$. Pada saat MPR, dipilih irisan paling tipis kondisi bone. Pilih menu CT Viewer dan atur slice thickness $25 \mathrm{~mm}$. Slice thickness yang digunakan minimal $25 \mathrm{~mm}$ sampai $50 \mathrm{~mm}$ karena disesuaikan dengan lebar cervical sekitar $50 \mathrm{~mm}$, bila digunakan $25 \mathrm{~mm}$ dilihat apakah ada fraktur atau tidak. Di bawah ini merupakan gambar radiograf hasil MPR.

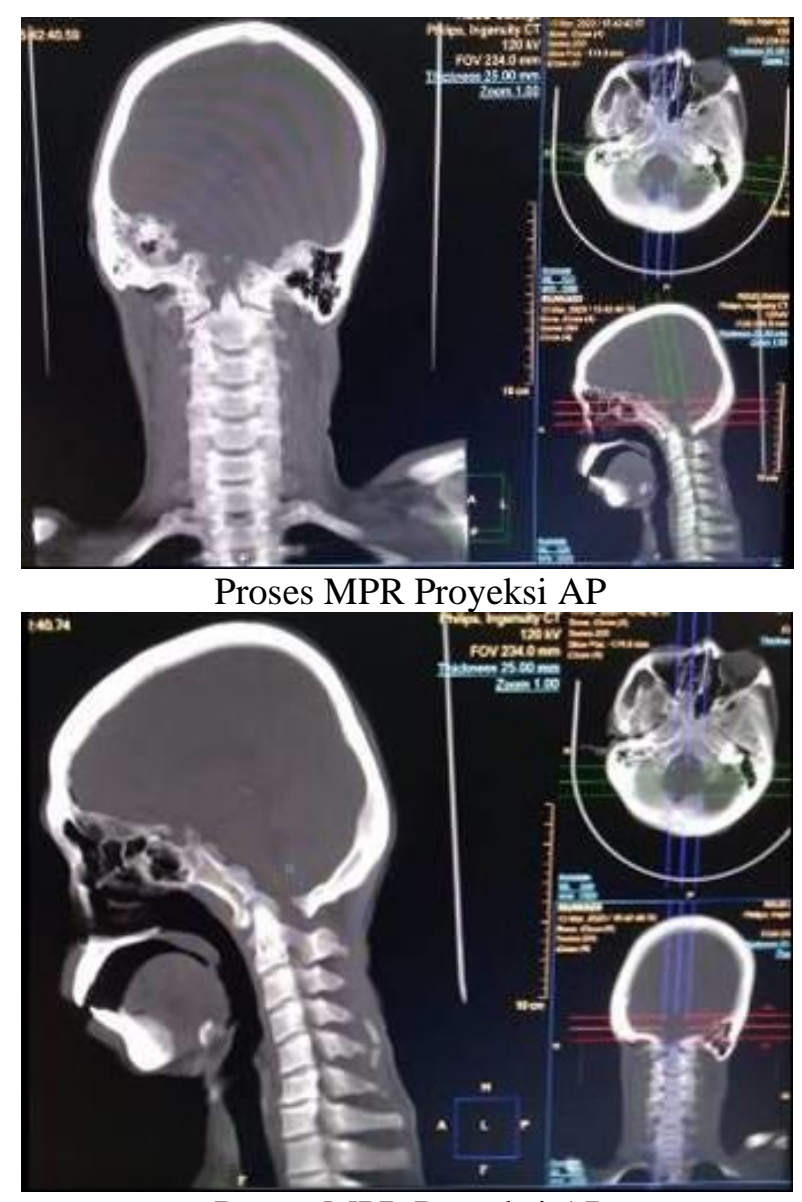

Proses MPR Proyeksi AP

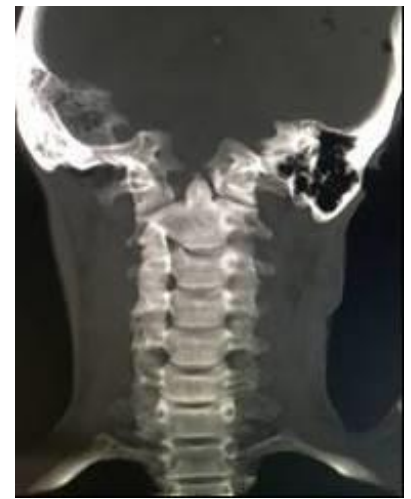

AP

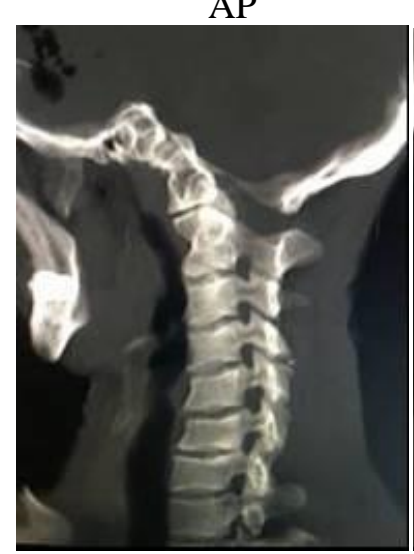

RPO

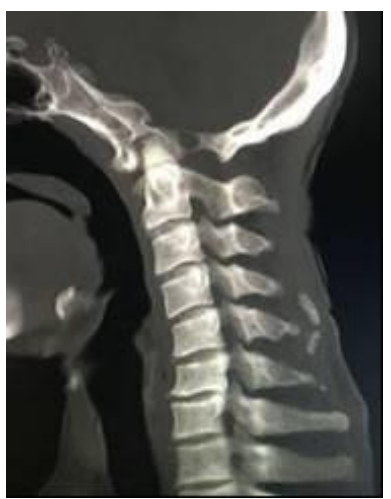

Lateral

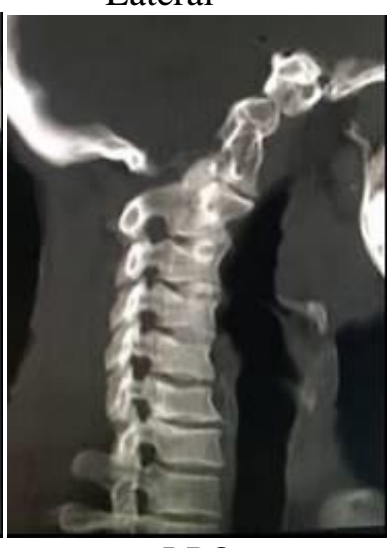

LPO 
Kelebihan gambaran hasil MPR potongan coronal, sagital, dan sagital obliq adalah tanpa merubah posisi pasien dapat diperoleh gambaran cervical proyeksi AP, lateral, dan obliq. Ketika pada kepala tidak ditemukan kelainan dokter dapat melihat gambaran cervical proyeksi AP, lateral, obliq dari tulangnya hingga foramennya. Gambaran MPR ini tidak ada superposisi, pada gambaran cervical proyeksi AP secara konvensional biasanya terlihat gambaran cervical 1 dan 2 superposisi dengan mandibula walaupun sudah disudutkan, serta pada proyeksi lateral gambaran cervical 7 superposisi dengan bahu. Kelemahannya dari dosis radiasi yang diterima pasien bertambah, namun pada pemeriksaan radiologi terdapat asas jastifikasi yaitu meskipun menggunakan CT-Scan dengan radiasi yang lebih besar tetapi manfaat yang diperoleh juga lebih besar.

Menurut European Journal Of Radiology 2019, penilaian dugaan cedera vertebra cervical masih menjadi perdebatan utama pada perawatan pasien trauma. Secara umum, terdapat fraktur pada korban trauma yang tidak sepenuhnya ditunjukkan pada radiografi karena korban trauma yang tidak kooperatif. Sebagian besar fraktur yang tidak dapat tervisualisasi terdapat pada level cervical 1 hingga cervical 2, cervical 6 hingga cervical 7, dan sebagian besar melibatkan processus transverses. Helical CT-Scan dapat menggambarkan fraktur yang signifikan yang tidak dapat ditunjukkan pada radiografi konvensional dan harus ditambahkan pada awal screening adanya dugaan trauma cervical.

Berdasarkan hasil penelitian dan dengan kajian teori dapat disimpulkan bahwa, informasi diagnostik yang diperoleh dari gambaran MPR potongan coronal, sagital, dan sagital obliq di Instalasi Radiologi RSUD Kota Salatiga sudah optimal sebagai pelengkap gambaran rekonstruksi CT-Scan lainnya dalam membantu dokter menegakkan diagnosa pada pasien dengan diagnosa cedera kepala sedang menggantikan gambaran cervical proyeksi AP, Lateral, RPO, dan LPO, sehingga harapannya tidak ada informasi diagnostik yang terlewat.

\section{Simpulan}

Gambaran cervical hasil MPR CT-Scan bertujuan memperoleh gambaran cervical proyeksi $\mathrm{AP}$, lateral, RPO, dan LPO tanpa dilakukan empat proyeksi secara konvensional dengan meminimalkan gerakan pada pasien dan meminimalkan resiko yang dapat memperberat cedera tulang belakang. Informasi diagnostik yang diperoleh dari gambaran cervical hasil rekonstruksi CT-Scan adalah mendapatkan visualisasi struktur spesifik, menentukan luasnya lesi atau fraktur, membantu melokalisasi lesi, fragmen tulang, atau benda asing. Terdapat fraktur pada korban trauma yang tidak sepenuhnya ditunjukkan pada radiografi pada level cervical 1 hingga cervical 2, cervical 6 hingga cervical 7, dan sebagian besar melibatkan processus transverses karena pasien tidak kooperatif. Helical CT-Scan dapat menggambarkan fraktur signifikan yang tidak dapat ditunjukkan pada radiografi konvensional dan harus ditambahkan pada awal screening adanya dugaan trauma cervical.

\section{Daftar Pustaka}

Ballinger Philip W, Eugene D. Frank. 2016. Merill's Atlas pf Radiographic Positioning and Radiographic Procedures, Twelfth Edition, Volume Three. St. Louis: Mostby

Bontrager, K.L 2018. Text book of Positioning and Related Anatomi, Ninth Edition. St. Louis: CV. Mostby Company

European Journal of Radiology.2019. Cervical Spine Trauma : How Much More Do We Learn by Routinely Using Helical CT? https://doi.org/10.1016/j.ejrad.2019.05.007. (diakses 22 Januari 2020 pukul 12.00 WIB)

Handoko, B.D, Ardiyanto, J, Nurcahyo, P.W. 2013. Optimalisasi Citra Rekonstruksi Multiplanar Pada Ct Wrist Joint Dengan Perubahan Slice Thickness Dan Reconstruction Interval. Jurnal Riset Kesehatan, 2(2),

DOI: 10.31983/irk.v2i2.203

Kiboi, Julius. 2019. Head Injury with Concurrent Cervical Spine Injury. International lisence. 16(1):11-15.

Malaysian Journal of Medical Sciences.2009. Calcification of the Alar Ligament Mimics Fracture of the craniovertebral Junction (CVJ) https://www.ncbi.nlm.nih.gov/pmc/articles/PMC3 216127/. (diakses 19 Mei 2020 pukul 16.00 WIB)

Nazir M, Khan SA, Raja RA, et al. Cervical spinal injuries in moderate to severe head injuries. J Ayub Med Coll Abbottabad. 2012; 24:3-4.

Pearce, E. C. 2017. Anatomi dan Fisiologi Untuk Paramedis. Penerbit PT. Gramedia Pustaka Utama. Jakarta.

Rawis, L. M. 2016. Profil pasien cedera kepala sedang dan berat yang dirawat di ICU dan HCU. Jurnal eClinic. 4(2) : 1-8.

Seeram, Eucli. 2016. Computed Tomography Physical, Prinsiples, Clinical Applications, and Quality Control. Fourth Edition. W.B Saunders Company.USA. Seeram, Eucli. 20016.

Suresh S. David. 2016. Clinical Pathways in Emergency Medicine. Volume II. Springer nature. 